\title{
Antibacterial potency and fluoride release of a glass ionomer restorative material containing different concentrations of natural and chemical products: An in-vitro comparative study
}

\author{
Hanaa Elgamily ${ }^{1}$, Omaima Ghallab ${ }^{2}$, Hoda El-Sayed ${ }^{3}$, Maha Nasr ${ }^{4,5}$ \\ ${ }^{1}$ Restorative and Dental Materials Department, Oral and Dental Division, National Research Centre, Giza, Egypt \\ ${ }^{2}$ Operative Dentistry Department, Faculty of Dentistry, Ain-Shams University, Cairo, Egypt \\ ${ }^{3}$ Dairy Science Department, Food Industries and Nutrition Division, National Research Centre, Giza, Egypt \\ ${ }^{4}$ Pharmaceutics and Industrial Pharmacy Department, Faculty of Pharmacy, Ain -Shams University, Cairo, Egypt \\ ${ }^{5}$ Pharmaceutics and Pharmaceutical Technology Department, College of Pharmaceutical Sciences, Mutah University, Jordan
}

Correspondence:

Restorative and Dental Materials Department

National Research Centre

33 El Bohouth st. (former El Tahrir st.)

Dokki- Giza- Egypt- P.O.12622

hanaa_elgamily@yahoo.com

Elgamily H, Ghallab O, El-Sayed H, Nasr M. Antibacterial potency and fluoride release of a glass ionomer restorative material containing different concentrations of natural and chemical products: An in-vitro comparative study. J Clin Exp Dent. 2018;10(4):e312-20.

Received: 30/12/2017 Accepted: 17/02/2018

http://www.medicinaoral.com/odo/volumenes/v10i4/jcedv10i4p312.pdf

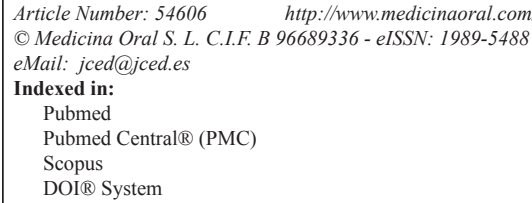

\begin{abstract}
Background: This study investigated the antibacterial efficacy against Streptococcus mutans and fluoride release of a conventional glass ionomer (GI) contained natural and chemical agents.

Material and Methods: Two hundred and ten GI specimens were divided into ten groups $(n=21)$ according to the concentrations of the additives as; Propolis extract containing GI (Groups 1, 2, 3) with concentrations of $0.25 \%$, $0.75 \%$ and $1.25 \%$ respectively, Miswak extract containing GI (Groups 4, 5, 6) and Chlorhexidine containing GI (Groups 7, 8,9) with the same concentrations. The prepared specimens were subjected to antimicrobial activity by well diffusion, bacterial adherence, and fluoride release (from 2 to 72 hours) assessments.

Results: A higher statistically significant antibacterial activity was found in (Groups 2,3) compared to (Groups 8, 9), while (Groups 1, 4, 5, 6, 7, 10) no antibacterial efficacy was reported. For (Groups 2, 3) had a higher statistically significant anti-adherence effect compared to the other tested groups. Enhanced ascending increase in fluoride release was observed for (Groups 3, 4) compared to (GI).

Conclusions: The increased concentration of propolis extract had a synergistic effect on the antimicrobial activity of the tested GI. Additive concentrations of $0.25 \%$ Miswak and $1.25 \%$ propolis could enhance the fluoride-releasing ability of the tested GI.
\end{abstract}

Key words: Propolis, miswak, chlorhexidine, glass ionomer, fluoride. 


\section{Introduction}

Despite the wide distribution of fluoride application especially in developed countries, dental caries remains one of the chronic diseases prevalent in humans worldwide (1-3). In developing countries due to the lack of facilities for dental treatment such as water and electricity for using dental handpieces and rotary burs, a manual instrumentation and atraumatic restorative treatment (ART), was elaborated (4). Lately, glass ionomer cements (GI) with enhanced physical strength were developed for ART but the ineffectiveness in complete removal of carious infected dentin, recurrent caries under GI restorations could produce (5-7). In addition, the previously dental literature showed a weak influence of GI releasing fluoride either on the profile growth of bacteria or the bacterial destruction (8). The possibility of microleakage and the limitations of GI's physical properties, lead to increase the risk for recurrent caries (7). Integrating antibacterial agents into glass ionomer materials might consequently, be acquired a therapeutic advantage. Lastly, researchers tried to modulate GI filling materials by adding chlorhexidine (CHX) and quaternary ammonium compounds (9). Some of dental literatures proved the increased antibacterial effect of CHX containing GI materials $(10,11)$. However, an optimal concentration of CHX which was not clearly identified as reported in many literatures and recommended to avoid any compromise of the mechanical and physical properties of the set cement (11-13). Anywise, use of natural agents against selected oral pathogens has been examined. Propolis, that's a natural product extensively used in the traditional medication from a long time ago, has proven its effectiveness against several types of bacteria and there are numerous products containing propolis on the world market inclusive of toothpaste and mouth rinses. Little investigations on the antibacterial efficacy of propolis using different concentrations were assessed against oral bacteria $(14,15)$. Furthermore, the use of plant extracts is one of the antibacterial approaches was investigated to improve caries control (16). In the Middle East, the most common traditional mean for oral hygiene is a chewing stick that is called miswak. Several studies reported the antibacterial activity of Miswak and its extracts against cariogenic bacteria $(17,18)$. Therefore, it is interesting to incorporate different concentrations of CHX, Ethanolic Propolis Extract and Aqueous Miswak Extract separately into GI to investigate; (1) their inhibitory activity and anti-adherence influence on Streptococcus mutans (ATCC 25175) and (2) their effect on the fluoride release comparing to GIC per se.

\section{Material and Methods}

1. Preparation of plant extract

- Ethanolic Extract of Propolis (EEP)

Propolis powder was obtained from a honey bee Egyptian supplier (Emtenan health shop, Cairo, Egypt). Thirty grams of propolis powder previously cooled $\left(\right.$ at $4{ }^{\circ} \mathrm{C}$ in a dark container) were mixed with $300 \mathrm{ml}$ of $5 \%$ ethanol $(1: 10 \mathrm{w} / \mathrm{v})$ and magnetically stirred for one hour, then stored for 48 hours at $4^{\circ} \mathrm{C}$. The storage mixture was centrifuged at 2000 rpm for 15 minutes, and then filtered with Whatman No. 4 (pore size, $0.45 \mu \mathrm{m}$ ). Finally, the previous filtered liquid was kept in freezer at $-20^{\circ} \mathrm{C}$ for 24 hours then lyophilized in a lyophilizer under $5 \mathrm{~mm} \mathrm{Hg}$ pressure at $-50^{\circ} \mathrm{C}(19,20)$. - Aqueous extract of Miswak

Salvadora persica plant specimens (Miswak sticks) from the Arak tree roots (Tybah Sewak, Madinah, KSA) were utilized. The collected plant sticks were left to dry at room temperature for 10 days, then they were cut into small pieces and powdered using a commercially available food blender (21). Three hundred $\mathrm{ml}$ of sterile distilled water was added to 30 grams of the previously prepared Miswak powder, then the mixture was magnetically stirred, centrifuged, filtered and lyophilized as previously mentioned in Ethanolic extract of Propolis.

2. Incorporation of ethanolic Propolis extract, aqueous Miswak extract, and chlorhexidine (CHX) separately into conventional glass ionomer (GIC) restorative material

Glass Ionomer Ionofil Plus (IP) (VOCO, GmbH, Cuxhaven, Germany) was selected for this research and provided in the form of separate powder and liquid bottles. - Preparation of Plant extract -containing Glass Ionomer restorative material

Propolis and miswak aliquots in Glass Ionomer (IP) powder, used in three different concentrations $0.25 \%, 0.75 \%$ and $1.25 \% \mathrm{w} / \mathrm{w}$ were prepared by trituration. Propolis and miswak in the form of powder were accurately weighed on a sensitive digital balance (Sartorius, Germany), followed by addition of equivalent weight of Glass Ionomer powder in a porcelain mortar. The powder was homogeneously mixed, followed by portion-wise addition of the whole amount of Glass Ionomer powder.

- Preparation of CHX-containing Glass Ionomer restorative material

Similarly, aliquots of Chlorehexidine Digluconate liquid (CHX) (Sigma Aldrich, Steinheim, Germany) was added to the polyalkenoic acid liquid component of Glass Ionomer (IP) in the form of three concentrations; $0.25 \%$, $0.75 \%$ and $1.25 \%(\mathrm{v} / \mathrm{v})$. Accurate volumes of (CHX) were taken by a micropipette (Gilson, UK) in a glass bottle, followed by the addition of polyalkenoic acid to create the aforementioned concentrations.

The incorporation of the plant extracts and (CHX) separately into Glass Ionomer Ionofil Plus restorative material was performed at the Department of Pharmaceutics and Industrial Pharmacy, Faculty of Pharmacy, Ain-Shams University, Cairo, Egypt.

3. Preparation of all groups of Conventional Glass Ionomer restorative material specimens 
For preparing Glass Ionomer (IP) (control) specimens, one scoop of powder to one drop of liquid was mixed on a glass plate according to manufacturer's recommendation (mixing ratio: 4.7-5.6 $\mathrm{g}$ of powder: $1 \mathrm{~g}$ of liquid). While for preparing Glass Ionomer material containing plant extract either EEP or Miswak specimens: one scoop of previously prepared Glass Ionomer (IP) powders containing one of the plant extracts with each selected concentration, was mixed to one drop of Glass Ionomer (IP) liquid. For preparing CHX-containing Glass Ionomer material specimens: one scoop of Glass Ionomer (IP) powder was mixed to one drop of previously prepared Glass Ionomer (IP) liquids containing CHX with the same three concentrations.

4. Study design

A total of two hundred and ten specimens of experimentally prepared Glass Ionomer restorative material were divided according to the type and concentrations of the additives that were incorporated into the Glass Ionomer (IP) as the following; Propolis extract containing Glass Ionomer (IP) (n=63) (groups: G1:GI+Propolis(0.25\%), G2:GI+Propolis $(0.75 \%)$, G3:GI+Propolis(1.25\%)) $(\mathrm{n}=21$ for each group); Miswak extract containing Glass Ionomer (IP) $(\mathrm{n}=63)$ (groups:G4:GI+Miswak $(0.25 \%)$, G5:GI+$\operatorname{Miswak}(0.75 \%), \mathrm{G6}: \mathrm{GI}+\operatorname{Miswak}(1.25 \%))(\mathrm{n}=21$ for each group); and CHX containing Glass Ionomer (IP) $(n=63)$ (groups:G7:GI+CHX(0.25\%), G8:GI+CHX(0.75\%), G9:GI+CHX(1.25\%) ( $=21$ for each group) and a group of Glass Ionomer (IP) without additive as a control $(\mathrm{n}=21)$. 5. Testing procedures

- Antimicrobial test

Streptococcus mutans ATCC 25175 type strain (16S rRNA gene, Serotype c. carious dentin) was obtained from (Microbiological Resources Centre, MIRCEN, Cairo, Egypt) and used throughout the study. Bacteria were cultured overnight at $37^{\circ} \mathrm{C}$ in the Brain Heart Infusion Broth (BHI, Merck KGaA 64271 Darmstadt, Germany) and used as inoculums. The turbidity of the suspension was adjusted to the McFarland 0.5 turbidity standard (Densimat, BioMerieux, France). At this absorbance, the concentration of bacteria is standardized to about $1 \mathrm{x} C F U / \mathrm{ml}$ and used as a working microbial solution (22).

Bacterial Inhibition Test

The antimicrobial activity of the three different concentrations $(0.25 \%, 0.75 \%$ and $1.25 \%)$ of each plant extract and CHX containing Glass Ionomer (IP) restorative material was assessed using well diffusion method. Twenty $\mu l$ of the previously prepared working microbial solutions was spread evenly over a trypticase soy agar plate (TSA, Difco, USA). The experimental Glass-Ionomer (IP) restorative material was mixed directly inside the wells with the powder/liquid ratio as described above, the mixing time was $30-40$ seconds, the working time was 2.5-3.5 minutes and the setting time (at ambient temperature) was 5-6 minutes. Five wells measuring 4 $\mathrm{mm}$ in diameter were made in each plate, three of these wells were filled with one of the selected concentration of each testing additives and the fourth well was filled with a Glass Ionomer (IP) without additive (control) $(\mathrm{n}=7$ plates per group). While the fifth one that was filled with $50 \mu \mathrm{l}$ of $0.2 \%$ chlorhexidine digluconate as a positive control against $\mathrm{S}$ mutans (23). After incubation of the plates at $37^{\circ} \mathrm{C}$ for 24 hours, the zones of bacterial growth inhibition around the wells were measured in $\mathrm{mm}$ unit.

Adherent/planktonic bacterial count test

A total of sixty-three specimens representing all groups (G1-G9) ( $\mathrm{n}=7$ per group) were performed by using cylindrical molds $(10 \mathrm{~mm}$ in diameter and $2 \mathrm{~mm}$ in thickness). Powder/Liquid ratio was mixed in accordance to the manufacturer instructions as previously mentioned for each group. After setting, each specimen was dipped separately into the test tube containing Tripticase Soy Broth media (TSB; Merck KGaA 64271 Darmstadt, Germany) supplemented with $5 \%(\mathrm{w} / \mathrm{v})$ sucrose. Twenty $\mu l$ of previously prepared suspension containing $S$. mutans ATCC 25175 (1x $\left.10^{-6} \mathrm{CFU} / \mathrm{ml}\right)$ was inoculated in each previous test tube and one test tube was left as a control without specimen. All testing tubes were incubated at $37 \mathrm{o} \mathrm{C}$ temperature for 24hours, while positioned at a 300 angle from the horizontal to increase the surface area for bacterial adherence. At the end of the incubation period, the TSB media, which contained non-adherent bacteria, was decanted, and the tubes were gently washed with $0.5 \mathrm{ml}$ of saline. The decanted broth and the washes were pooled, centrifuged, and suspended in saline. The adhering bacteria to the glass were removed by $0.5 \mathrm{M} \mathrm{NaOH}$, centrifuged, and suspended in saline $(24,25)$. Each suspension containing non-adherent bacteria and adherent bacteria of each group separately was vortexed for two minutes and sonicated for one minute. Then, dilutions of $1 \times 10^{-2}$ and $1 \times 10^{-3}$ of saline containing previously vortexed and sonicated suspension were performed (22). Thirty $\mu$ l of each dilution was spread on the surface of selective media Mitis Salivarius Bacitracin (MSB; BD Difco, France) plate. After incubation period of 24- 48 hours, the suspension containing either adherent or non-adherent (planktonic) bacteria were counted to determine the number of colony forming unit per $\mathrm{ml}(\mathrm{CFU} / \mathrm{ml})$.

- Measurements of fluoride ions release

Seven specimens for each group were prepared using a split Teflon mold with a diameter of $5 \mathrm{~mm}$ and a thickness of $1 \mathrm{~mm}$, with powder/liquid ratio as described by the manufacturer. After setting, each specimen was placed in $10 \mathrm{ml}$ deionized water $(\mathrm{pH} \sim 7)$ and stored at $37^{\circ} \mathrm{C}$. The specimens were transferred to new vials with renewed deionized water for 2, 6, 12, 24, and 72 hours measuring times. Accompanying the transition to new 
vials, the old deionized water was stored at $-20^{\circ} \mathrm{C}$ in order to perform all fluoride concentration analyses in one session. The specimens were filtered on Merman filter paper then measured on the Ion Chromatography ICs $5000+$ SP (Thermo scientific, USA) which consisting of a P680 pump, an automated sample injector. Data collection and processing were performed with a personal computer equipped with Dionex Chromeleon software. The measurement unit is $\mathrm{mg} / \mathrm{l}$ or $\mathrm{ppm}$. The specimens were analyzed at (Water Pollution Research Department, Environmental Research Department, National Research Centre, Egypt).

6. Statistical analysis

Data were explored for normality using Kolmogorov-Smirnovand Shapiro-Wilk tests. For parametric data; One-way ANOVA followed by Tukey post-hoc test was used to compare between more than two groups in non-related samples. For non-parametric data; Kruskal Wallis test was used to compare between more than two groups in non-related samples. Mann Whitney was used to compare between two groups in non-related samples. The mean and standard deviation values were calculated for each group in each test. The significance level was set at $\mathrm{P} \leq 0.05$. Statistical analysis was performed with IBM $®$ SPSS $®$ Statistics Version 20 for Windows.

\section{Results}

1. Inhibition zones results

According to well diffusion test results, the means of the inhibition zones diameter $(\mathrm{mm})$ for the studied groups against $S$. mutans were displayed in (Fig. 1).
The size of inhibition zones of GI containing propolis were obviously dependent on the three different concentrations $(0.25 \%, 0.75 \%$, and $1.25 \%)$ of Propolis where $(P \leq 0.001)$. The highest statistically significant mean value was found in (G3 1.25\%) (32.60 \pm 2.22$)$ compared to $(\mathrm{G} 20.75 \%)(23.30 \pm 4.45)$ and $\mathrm{CHX}$ per se (control group) (25.80 \pm 1.23$)$, while in (G1 $0.25 \%$ ), it did not exhibit any antibacterial efficacy against $S$. mutans as well as the three concentrations of GI containing Miswak in (G4 0.25\%), (G5 0.75\%) and (G6 1.25\%). For GI containing $\mathrm{CHX}$, the concentration $0.75 \%$ (G8) and $1.25 \%$ (G9) showed an inferior statistically significant inhibitory activity against $S$. mutans compared to (G2), (G3) where $(\mathrm{P} \leq 0.001)$. The control group Glass ionomer (GI) did not show any antibacterial efficacy against $S$. $m u$ tans.

2. Bacterial count results

- The Planktonic Bacterial count

The effect of different additive's concentrations in each group regarding the planktonic bacterial count of $S$. $m u$ tans was represented in (Fig. 2). For GI containing propolis groups, a lower statistically significant mean CFU/ $\mathrm{ml}$ value of planktonic bacterial count reported for (G1) compared to the other additives groups. While in (G2), (G3), lack of CFU/ml of planktonic bacteria was noticed.

For (G4), (G5) and (G6) of GI containing Miswak, there was no statistically significant difference between the mean values of $\mathrm{CFU} / \mathrm{ml}$ of planketonic bacteria $(3.87 \pm 0.06,3.84 \pm 0.07,3.81 \pm 0.06)$ respectively, where $P$ value $=0.4$.

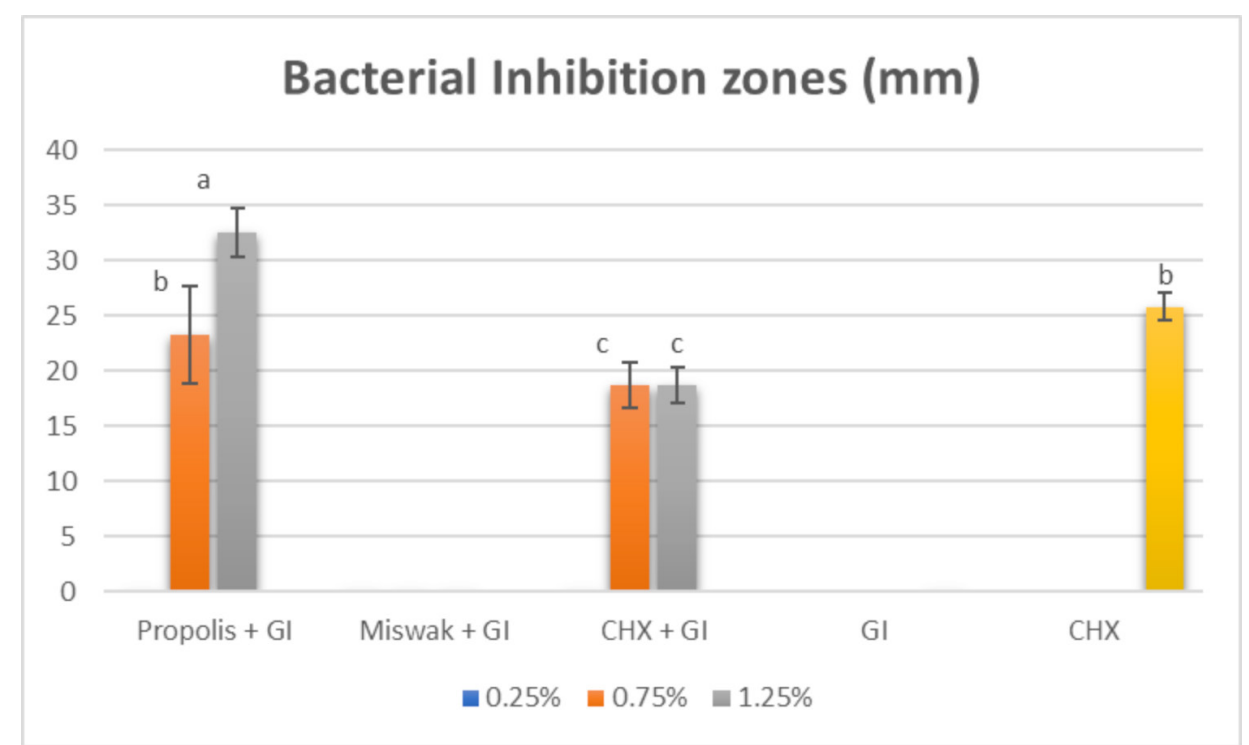

Fig. 1: Bar chart representing the means of inhibition zones $(\mathrm{mm})$ for different concentrations in all tested groups. 


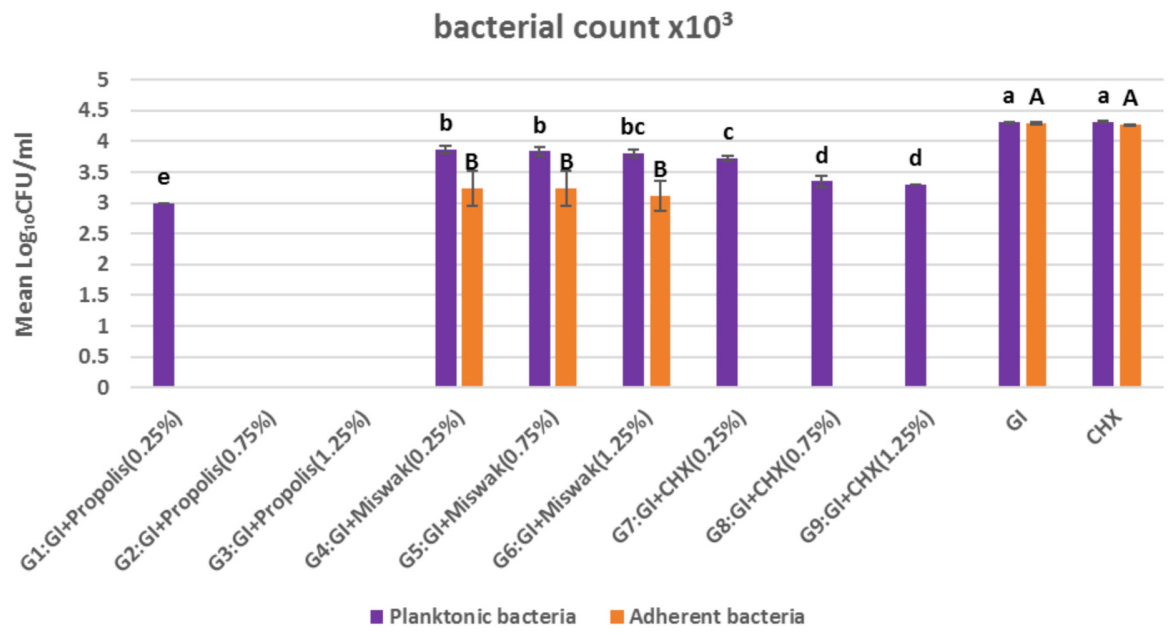

Fig. 2: Bar chart representing the means of planktonic and adherent bacterial count (CFU/ml) for all tested groups.

For the Groups of CHX containing GI, (G7) showed a higher statistically significant mean value of $\mathrm{CFU} / \mathrm{ml}$ of planketonic bacteria $(3.72 \pm 0.04)$ compared to $(\mathrm{G} 8)$ and (G9) $(3.35 \pm 0.09,3.30 \pm 0.00)$ where $P$ value $=0.008$. There was no statistical significant difference between (G8) and (G9).

Moreover, (GI) and CHX control groups showed higher statistically significant mean values of $\mathrm{CFU} / \mathrm{ml}$ of planktonic bacterial count compared to the other groups.

- Adherent Bacterial Count:

The Propolis containing GICs groups (G1, G2, G3) recorded lack of $\mathrm{CFU} / \mathrm{ml}$ of adherent bacterial count. While Miswak containing GI groups (G4, G5, G6) exhibi- ted no statistically significant difference regarding the mean values of adherent bacterial count $(3.24 \pm 0.028$, $3.24 \pm 0.28,3.12 \pm 0.24$ ) respectively where $P$ value $=0.4$. CHX containing GI groups (G7, G8, G9) showed absence of adherent bacterial count. GI and CHX control groups reported higher statistically significant mean values of adherent bacterial count compared to the other groups $(4.30 \pm 0.02,4.27 \pm 0.01)$ respectively and there was no statistical significant difference between them.

3. Fluoride release results

In (Fig. 3), the mean values of fluoride release (ppm) for (G1), (G2), (G5), (G6), (G7), (G8) and (G9) showed an increase from 2 hours measuring time till 12 hours,

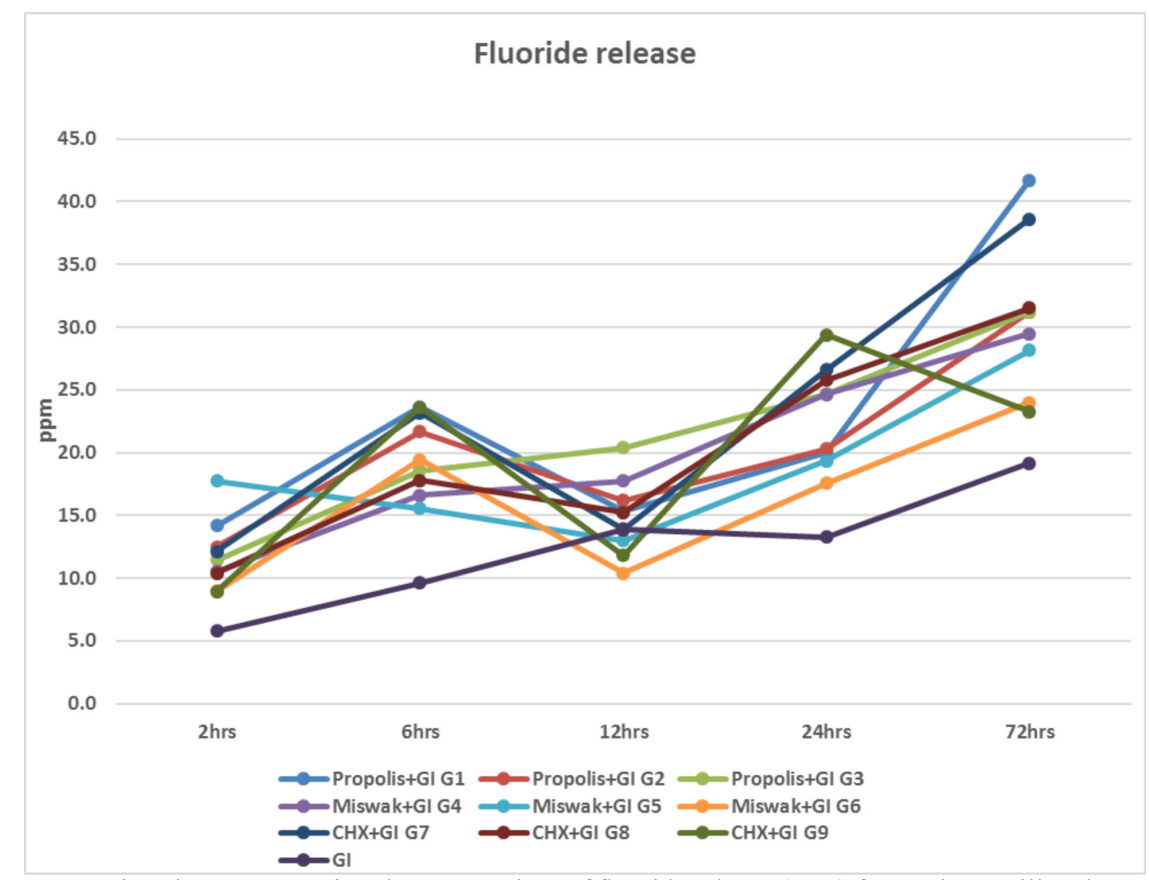

Fig. 3: Line chart representing the mean values of fluoride release (ppm) from 2 hours till 72 hours measuring times for all the tested groups. 
then it decreased after reaching 12 hours. Finally, the mean values of fluoride release elevated again till reaching 72 hours. While for (G3), (G4) and conventional glass ionomer control group (GI), the mean values of fluoride release increased from 2 hours measuring time till reaching 72 hours without decreasing at any time of measurements.

\section{Discussion}

Caries ailment still remains a noteworthy general medical issue regardless of the boundless utilization of fluoride and the decrease in caries commonness saw in the larger part of exceedingly industrialized countries (3). The utilization of Glass Ionomer cements (GI) as an antibacterial remedial material for the treatment of caries is dicey on account of the possible microleakage and impediments related with their physical properties (7). However, annual scientific research reported that the main cause for GI failure is still the recurrent caries (26-28). Therefore, combining bactericidal agent with Glass Ionomer materials would provide an alternative approach. Overtures, numerous trials for the enhancement of the antibacterial characteristic of GICs have been documented by means of the addition of antibacterial solutions like chlorhexidine (CHX) (29,30). Notwithstanding, an ideal convergence of $\mathrm{CHX}$ was prescribed to keep away from any trade off of the mechanical and physical properties of the set cement $(12,13)$. The use of plant extracts is one of the many approaches investigated for caries control (16). Miswak extract is a medicinal plant that reported to have anti-plaque and many other pharmacological properties (31). Also, it is cheap and its taste is agreeable and not unpleasant. As well, Propolis extract which is a natural non-toxic substance produced by the honeybee appears a modern choice as it is inexpensive and available without difficulty and also, possessed many biological therapeutic activities (32). With regard to previously mentioned knowledge, three remarkable antimicrobial agents; chlorhexidine digluconate (CHX), ethanolic extract of Propolis (EEP), and aqueous Miswak extract were selected for this in-vitro study in the form of three different concentrations and incorporated into conventional GI restorative material. S. mutans is a solitary bacterial biofilm and has been utilized as a part of a few past investigations of antibacterial dental materials as a result of its involvement with dental caries (33-36). Therefore, S. mutans was chosen for the present study to screen the antibacterial activity of each natural antimicrobial agents incorporating into GI at three different concentrations $(0.25 \%, 0.75 \%$, $1.25 \%$ ) using agar plate diffusion method.

Agar plate diffusion was a preferable method in the current research due to its facilities to investigate the unset materials with a massive range of specimens and also, it is less expensive. Unfortunately, the inhibition zone observed through that test does not represent any data about the viability of the examined microorganisms as it could not be able to differentiate between the bacteriostatic and the bactericidal effects (12). Moreover, the in-vitro check does not confer with the clinical reality wherein various species of bacteria may be developing in complex biofilms.

As it was reported in the literature that, the materials had appreciably more antibacterial effect for the unset state than the completely set one (38). This could be attributed to the initial bactericidal efficacy of the most dental materials while setting and their low $\mathrm{pH}$ throughout this time might too have an impact. Therefore, this current study used the unset conventional GI material to be examined with the well diffusion method based on the previous findings (12).

According to well diffusion test results (Fig. 1), the tested groups of GIC containing EEP (G1, G2, G3) showed that, the inhibition zones diameters that were created against $S$. mutans growth have been virtually based upon the concentration of the EEP introduced into the GI. This previous observation validated that the addition of EEP to Glass ionomer Ionofil Plus (IP) led to a restorative material that had improved antibacterial properties over the traditional glass ionomer per se concerning S. mutans growth. However, the findings of this study were in contrast to Nursen Topcuoglu et al. (22); who reported that diameters of inhibition zones which were determined against $S$. mutans were not based upon the concentration of EEP. The difference could be attributed to the significant variations between the laboratories; the determination of inhibition zones values was also linked to the inherent virulence of bacteria and their susceptibility (39).

While there were no inhibition zones exhibited by the tested groups of GI containing Miswak and revealed no statistically significant difference between them; (G4 $0.25 \%),(\mathrm{G} 5$ 0.75\%) and (G6 1.25\%). The latter result could be due to incorporation of three different low concentrations into the GI which were ineffective. This was in agreement with a previous study conducted by Kabil et al. (40); who demonstrated that the antimicrobial effect increased significantly by adding higher concentrations of Miswak into GI.

Preceding researches the usage of traditional GI tested conflicting outcomes about the antibacterial effect determined through the addition of CHX; some pronounced that antimicrobial activity was based upon the concentration of the disinfectant delivered to GI $(10,4,30)$, whilst others indicated no dose-response impact $(1,42)$. The results in the current study revealed a higher statistically significant difference between the concentrations of $0.75 \%(\mathrm{G} 8)$ and $1.25 \%(\mathrm{G} 9)$ compared to the concentration of $0.25 \%$ (G7) as in (Fig. 1), and this would correlate the elution rate of the antibacterial agent from 
the GI with a specific concentration, where synergism has been appeared to happen between the metal particles and the cationic CHX antibacterial agent (30).

Regarding to the adherent bacterial count assay, this present study described the development of an assay based on the ability of each plant extract and CHX containing GI to inhibit adherence of Streptococcus mutans (25175) to glass surfaces. Using a smooth glass surface in this study to symbolize the hard surface of the tooth and prove to be equally fine as adherence model compared to hydroxyapatite or a tooth surface (43). Adhesion of cariogenic streptococci to the smooth surfaces of teeth and restoration surfaces is a very essential level within the pathogenesis of dental caries. This adherence can mimic in-vitro and needs sucrose within the growth media, which acts as the principle direction that helps bacterial adherence to surfaces. $S$. mutans have the ability to convert the sucrose into glucans which reinforce the adhesion and consequently gives a share in dental biofilm formation. As documented that, the adherent bacteria are greater resistant than their planktonic forms in biofilms, in-vitro assay could simulate the clinical testing of anti-plaque property of different restorative materials (22).

The results in (Fig. 2) showed that EEP containing GI had a statistically significant anti-adherence effect on $S$. mutans compared to the other tested groups. S. mutans serotype c is especially hydrophobic, and that hydrophobic bonding regarded to be a crucial element of their adherence activities. It is consequently advised that anti-adherence activities of EEP containing GI as shown in the results could have been altered this natural hydrophobic bond which in the midst of the bacteria and the smooth glass surfaces (44). While the lower anti-adherence activities of CHX containing GIC than EEP containing is probably a result of the material wastage via elution. Another explanation, as has been advised with the aid of Ribeiro and Ericson (10); the lower in CHX is associated with the formation of insoluble salts with the GI. The groups of Miswak containing GI as shown in (Fig. 2), no statistically significant difference in CFU/ $\mathrm{ml}$ of adherent bacteria was reported between (G4), (G5) and (G6) as well as for planktonic bacteria, while a statistically significant difference was found between each of them and all other groups. This previous finding could be due to the active volatile components of Miswak extract in GI might be lost during its preparation (45). Therefore, the adherence inhibition assay was shown to be effective and reproducible in quantitating the ability of each plant extract and CHX incorporating into GI to prevent the adherence of $S$. mutans (25175 serotype c) to the smooth glass surfaces.

The mean values of fluoride release results in ( $\mathrm{ppm})$ unit of Glass Ionomer specimens after the addition of different concentrations of plant extract (EEP, Miswak) and CHX individually is presented in (Fig. 3). The results reported that, the incorporation of $0.25 \%(\mathrm{G} 1)$ and $0.75 \%$ (G2) into GI elevated the release of fluoride at 6 hours measuring time. After GI specimens setting, it decreased after reaching 12 hours, finally fluoride elevated in release again till reaching 72 hours. While the concentration of $1.25 \%$ of EEP in GI (G3) increased in release from two hours measuring time till reaching 72 hours without decreasing at any time of measurements. This latter finding could be due to the physical presence of EEP in the matrix of GIC that might help in creating a route for the emission of fluoride. It also could be explained by the increased solubility of GIC by adding EEP, which might give rise to the fusillade release of fluoride in the early 12 hours after specimens setting (8). Therefore, the experimental GI with EEP had improved the antimicrobial properties of GI with conservation the retentive characteristics of fluorine ion release when compared to conventional GICs per se.

Regarding the results of Miswak containing GI (G4, G5, G6), the selected concentrations exhibited increase of fluoride release at the different times of measurement except for (G5, G6), which showed a decrease in fluoride release at 12 hours measuring time followed by increase until reaching 72 hours. It was obviously noticed that addition of Miswak with different concentrations had increased the fluoride release compared to the conventional GI per se. This might be due to the ability of Miswak to release fluoride. It was in contrast to several studies, where they reported that Miswak extract could release fluoride but it was considered unlikely, as it is soluble and fluoride total content in the Miswak, especially that released when soaked in water, is negligible $(<0.07$ $\mu \mathrm{g} / \mathrm{ml}$ ) (46-48). At 12 hours measuring time, fluoride release was decreased, this might be due to the chemical reaction between fluoride and any of the organic or inorganic substances present in Miswak extract that protected or inhibited the release of fluoride as suggested by Morch and Bjorvatn (49).

It was observed that, the fluoride release for (G7), (G8) and (G9) of CHX containing GI was lower at 12 hours measuring time, then it increased till reaching 72 hours. This might be explained Hoszek and Ericson (13); who found that the association amongst fluoride and the cationic CHX, bringing about the precipitation of salts with bring down dissolvability, leaving fluoride less accessible during the setting of the conventional GI.

In conclusion, within the limitations of this study and the persistent changes of the oral environment, the following conclusions could be drawn: The increased concentration of propolis extract had a synergistic effect on anti-microbial activity of the tested conventional GI. As well, the additive concentrations of $0.25 \%$ Miswak and $1.25 \%$ propolis could enhance the fluoride releasing ability of the tested conventional GI. 


\section{References}

1. Selwitz RH, Ismail AI, Pitts NB. Dental caries. Lancet. 2007;369:518.

2. Hu DY, Hong X, Li X. Oral health in China trends and challenges. Int J Oral Sci. 2011;3:7-5.

3. Marthaler TM. Changes in dental caries 1953-2003. Caries Res. 2004;38:173-81.

4. Frencken JE, Makoni F. A treatment technique for tooth decay in deprived communities. World Health. 1994;1:15-7.

5. Phantumvanit $P$, Songpaisan Y, Pilot T, Frencken JE. Atraumatic restorative treatment (ART): a three-year community field trial in Thailand -survival of one surface restorations in the permanent dentition. J Public Health Dent. 2005;23:275-5.

6. Weerheijm KL, Kreulen CM, de Soet JJ, Groen HJ, van Amerongen WE. Bacterial counts in carious dentine under restorations: 2-year in vivo effects. Caries Res. 1999;33:130-4.

7. Van Amerongen WE. Dental caries under glass ionomer restorations. J Public Health Dent. 1996;56:150-4.

8. Wang SP, Yang Ge, Zhoul XD, Hockin HX, Weir MD, Zhang $\mathrm{KK}$, Wang HH, et al. Effect of anti-biofilm glass-ionomer cement on Streptococcus mutans biofilms. International Journal of Oral Science. 2016;8:76-7.

9. Imazato S. Antibacterial properties of resin composites and dentin bonding systems. Dent Mater. 2003;19:449-8.

10. Ribeiro J, Ericson D. In vitro antibacterial effect of chlorhexidine added to glass ionomer cements. Scand J Dent Res. 1991;99:533-7.

11. Takahashi Y, Imazato S, Kaneshiro AV, Ebisu S, Frencken JE, Tay FR. Antibacterial effects and physical properties of glass-ionomer cements containing chlorhexidine for the ART approach. Dent Mater. 2006;22:647-5

12. Turkun LS, Turkun M, Ertugrul F, Ates M, Brugger S. Long term antibacterial effects and physical properties of a chlorhexidine-containing glass ionomer cement. J Esthet Restor Dent. 2008;20:29-15.

13. Hoszek A, Ericson D. In vitro fluoride release and the antibacterial effect of glass ionomers containing chlorhexidine gluconate. Oper Dent. 2008;33:696-1.

14. Santos FA, Bastos EM, Uzeda M, Carvalho MA, Farias LM, Moreira ES, et al. Antibacterial activity of Brazilian propolis and fractions against oral anaerobic bacteria. J Ethnopharmacol. 2002 80:1-7.

15. Park YK, Koo H, Abreu JA, Ikegaki M, Cury JA, Rosalen PL. Antimicrobial activity of propolis on oral microorganisms. Current Microbiology. 1998;36:24-4.

16. Ten Cate JM. The need for antibacterial approaches to improve caries control. Adv Dent Res. 2009;21:8-12.

17. Abo Al-Samh DA and Al-Bagieh N. A study of antibacterial activity of the Miswak extract in vitro. Biomed Lett. 1996;53:225-13.

18. Almas K, Al-Bagieh N, Akpata ES. In Vitro antibacterial effect of freshly cut and 1-month-old Miswak extracts. Biomedical letters. 1997;56:145- 4.

19. Jafarzadeh TS, Kermanshahi RK, Erfan M, Dastjerdi EV, Rezaei Y, Tabatabaei FS. Evaluating the In-vitro Antibacterial Effect of Iranian Propolis on Oral Microorganisms. Iranian Journal of Pharmaceutical Research. 2011;10:363-5.

20. Yang HY, Wei-Li HO, Chang CM, Chou CC. Antbacterial activity of propolis ethanol extract against Streptococcus mutans as influenced by concentration, temperature, $\mathrm{pH}$ and cell age. J. Food Drug Anal. 2007;15:75-6.

21. Al- bayati FA and Sulaiman KD. In Vitro Antimicrobial Activity of Salvadora persica L. Extracts Against Some Isolated Oral Pathogens in Iraq. Turk J Biol. 2008;32:57-5.

22. Nursen Topcuoglu, Fatih Ozan, Mustafa Ozyurt, and Guven Kulekci. In vitro antibacterial effects of glass-ionomer cement containing ethanolic extract of propolis on Streptococcus mutans. Eur J Dent. 2012;6:428-5.

23. Akca A E, Akca G, Topçu F T, Macit E, Pikdoken L, Ozgen I S. The Comparative Evaluation of the Antimicrobial Effect of Propolis with Chlorhexidine against Oral Pathogens: An In Vitro Study. BioMed Res Inter. 2016;2016:3627463.
24. Farid A. Badria and Omar A. Zidan. Natural Products for Dental Caries Prevention. J Med Food. 2004;7:381-3.

25. Gerald A. Olson, Arnold S. Bleiweis, Parker A. Small, JR. Adherence Inhibition of Streptococcus mutans: An Assay Reflecting a Possible Role of Antibody in Dental Caries Prophylaxis. Infection and Immunity. 1972;5:419-8.

26. Mjör IA, Dahl JE, Moorhead JE. Placement and replacement of restorations in primary teeth. Acta Odontol Scand. 2002;60:25-3.

27. Forss H, Widström E. Reasons for restorative therapy and the longevity of restorations in adults. Acta Odontol Scand. 2004;62:82-4.

28. Wiegand A, Buchalla W, Attin T. Review on fluoride-releasing restorative materials fluoride release and uptake characteristics, antibacterial activity and influence on caries formation. Dent Mater. 2007;23:343-9.

29. Frencken JE, Imazato S, Toi C, Mulder J, Mickenautsch S, Takahashi Y, Ebisu S. Antibacterial effects of chlorhexidine containing glass ionomer cement in vivo A pilot study. Caries Res. 2007;41:102-5. 30. Deepalakshmi M, Poorni S, Miglani R, Rajamani I, Ramachandran $\mathrm{S}$. Evaluation of the antibacterial and physical properties of glass ionomer cements containing chlorhexidine and cetrimide: an in-vitro study. Indian J Dent Res. 2010;21:552-4.

31. Mohammed SG. Comparative study of in vitro antibacterial activity of Miswak extracts and different toothpastes. American Journal of Agricultural and Biological Sciences. 2013;8:82-6.

32. Kashi TS, Kermanshahi RK, Erfan M, Dastjerdi EV, Rezaei Y and Tabatabaei FS: Evaluating the In-vitro Antibacterial Effect of Iranian Propolis on Oral Microorganisms. Iranian Journal of Pharmaceutical Research. 2011;10:363-5.

33. Xie D, Weng Y, Guo X, Zhao J, Gregory RL, Zheng C. Preparation and evaluation of a novel glass-ionomer cement with antibacterial functions. Dent Mater. 2011;27:487-9.

34. Hu J, Du X, Huang C, Fu D, Ouyang X, Wang Y. Antibacterial and physical properties of EGCG-containing glass ionomer cements. J Dent. 2013;41:927-7.

35. Moye ZD, Zeng L, Burne RA. Fueling the caries process: carbohydrate metabolism and gene regulation by Streptococcus mutans. J Oral Microbiol. 2014;6:24878.

36. Zhang S. Dental caries and vaccination strategy against the major cariogenic pathogen, Streptococcus mutans. Curr Pharm Biotechnol. 2013;14:960-6.

37. Herrera M, Castillo A, Baca P, Carrion P. Antibacterial activity of glass-ionomer restorative cements exposed to cavity producing microorganisms. Oper Dent. 1999;24:286-5.

38. Coogan MM, Creaven PJ. Antibacterial properties of eight dental cements. Int Endod J. 1993;26:355-5.

39. Dziedzic A, Kubina R, Robert D, Wojtyczka RD, Dzik AK, Tanasiewicz M, et al. The antibacterial effect of polish propolis on Mutans streptococci and Lactobacilli isolated from saliva. Evidence-Based Complementary and Alternative Medicine, Article. 2013;1:1-2.

40. Kabil NS, Badran AS, Wassel MO. Effect of the addition of chlorhexidine and miswak extract on the clinical performance and antibacterial properties of conventional glass ionomer: an in vivo study. Int $\mathrm{J}$ Paediatr Dent. 2017;27:380-7.

41. Sanders BJ, Gregory RL, Moore K, Avery DR. Antibacterial and physical properties of resin modified glass-ionomers combined with chlorhexidine. J Oral Rehabil. 2002;29:553-8.

42. Jedrychowski J, Caputo A, Kerper S. Antibacterial and mechanical properties of restorative materials combined with chlorhexidines. J Oral Rehabil. 1983;10:373-8.

43. Matsumoto Nakano M. Role of Streptococcus mutans surface proteins for biofilm formation. Japanese Dental Science Review (2017). 44. Razak FA and Abd Rahim ZH. The anti-adherence effect of Piper betle and Psidium guajava extracts on the adhesion of early settlers in dental plaque to saliva-coated glass surfaces. Journal of Oral Science. 2003;45:201-5.

45. Khalessi AM, Pack ARC, Thomson WM, Tompkins GR. An in vivo study of the plaque control efficacy of Persica TM: a commercially available herbal mouthwash containing extracts of Salvadora persica. International Dental Journal. 2004;54:279-4. 
46. Hattab F: Meswak: the natural toothbrush. J. Clin. Dent. 1997;8:125-4.

47. Wu CD, Darout IA, Skaug N. Chewing sticks: timeless natural toothbrushes for oral cleansing. J Period Res 2001;36:275-9.

48. Al-Otaibi M, Al-Harthy M, Gustafsson A, Johansson A, Claesson R, Angmar-Mansson B. Subgingival plaque microbiota in Saudi Arabians after use of miswak chewing stick and toothbrush. J Clin Periodontol. 2004;31:1048-5.

49. Morch T, Bjorvatn K. Laboratory study of fluoride impregnated toothpicks. Scand.J. Dent. Res. 1981;89:499-6.

Acknowledgment

The authors thank the continuous positive emotional support of late Dr. Mokhtar N Ibrahim, Professor of Operative Dentistry, Faculty of Dentistry, Ain-Shams University. Forever appreciated and engraved in our minds.

\section{Conflicts of interest}

Each author has no conflicts of interest. 